\title{
Two membrane-bound transcription factors regulate expression of various type-IV-pili surface structures in Sulfolobus acidocaldarius
}

\author{
Lisa Franziska Bischof ${ }^{1,2}$, Maria Florencia Haurat ${ }^{3}$, Sonja-Verena Albers ${ }^{\text {Corresp. } 1}$ \\ 1 Institute of Biology II, Molecular Biology of Archaea, University of Freiburg, Freiburg, Germany \\ 2 Spemann Graduate School of Biology and Medicine (SGBM), Freiburg, Germany \\ 3 Department of Molecular Microbiology, Washington University, School of Medicine in St. Louis, Missouri, USA \\ Corresponding Author: Sonja-Verena Albers \\ Email address: sonja.albers@biologie.uni-freiburg.de
}

In Archaea and Bacteria, gene expression is tightly regulated in response to environmental stimuli. In the thermoacidophilic crenarchaeon Sulfolobus acidocaldarius nutrient limitation induces expression of the archaellum, the archaeal motility structure. This expression is orchestrated by a complex hierarchical network of positive and negative regulators - the a rchaellum r egulatory $n$ etwork (arn). The membrane-bound one-component system ArnR and its paralog ArnR1 were recently described as main activators of archaellum expression in S.acidocaldarius.They regulate gene expression of the archaellum operon by targeting the promoter of $f l a B$, encoding the archaellum filament protein. Here we describe a strategy for the isolation and biochemical characterization of these two archaellum regulators. Both regulators are capable of forming oligomers and are phosphorylated by the Ser/Thr kinase ArnC. Apart from binding to pflaB, ArnR but not ArnR1 bound to promoter sequences of aapF and ups $X$, which encode components of the adhesive (Aap) and UV inducible pili (Ups), demonstrating a regulatory connection between different surface appendages of S.acidocaldarius. 
1 Two membrane-bound transcription factors regulate expression of various type-IV-pili

2 surface structures in Sulfolobus acidocaldarius

3

4 Lisa Franziska Bischof ${ }^{1,2}$, Maria Florencia Haurat ${ }^{3}$ \& Sonja-Verena Albers $^{1}$

5

$6{ }^{1}$ University of Freiburg, Institute for Biology II, Molecular Biology of Archaea, Freiburg,

7 Germany; ${ }^{2}$ Spemann Graduate School of Biology and Medicine (SGBM), Freiburg, Germany, ${ }^{3}$

8 Department of Molecular Microbiology, Washington University, School of Medicine in St.

9 Louis, Missouri, USA

10

11 Corresponding Author:

12 Sonja-Verena Albers ${ }^{1}$

13 Schaenzlestrasse 1, 79104 Freiburg, Germany

14 Email address: sonja.albers@biologie.uni-freiburg.de 


\section{Abstract}

17

18 In Archaea and Bacteria, gene expression is tightly regulated in response to environmental

19 stimuli. In the thermoacidophilic crenarchaeon Sulfolobus acidocaldarius nutrient limitation 20 21 2

\section{3}

\section{4}

\section{5}

\section{6} 27

\section{8}

29
induces expression of the archaellum, the archaeal motility structure. This expression is orchestrated by a complex hierarchical network of positive and negative regulators - the

22 archaellum regulatory network ( $\underline{\operatorname{arn}})$. The membrane-bound one-component system ArnR and its 23 paralog ArnR1 were recently described as main activators of archaellum expression in 24 S. acidocaldarius. They regulate gene expression of the archaellum operon by targeting the 25 promoter of $f l a B$, encoding the archaellum filament protein. Here we describe a strategy for the 26 isolation and biochemical characterization of these two archaellum regulators. Both regulators 27 are capable of forming oligomers and are phosphorylated by the Ser/Thr kinase ArnC. Apart 28 from binding to $p f l a B$, ArnR but not ArnR1 bound to promoter sequences of aapF and ups $X$, 9 which encode components of the adhesive (Aap) and UV inducible pili (Ups), demonstrating a 30 regulatory connection between different surface appendages of $S$. acidocaldarius. 


\section{Introduction}

32 Stress response that yields adaptation to changing environmental conditions is one of the most

33

34

35

36

37

38

39

40

41

42

43

44

45

46

47

48

49

50

51

52

53

54

55

56

57

58

59

60

61

important prerequisites to ensure survival in prokaryotes. Various signal transduction modules have evolved to receive, transfer and process extracellular signals in the cell (Esser et al., 2016; Koretke et al., 2000; Ulrich et al., 2009). In response to these signals, transcription factors regulate and adjust gene expression to ensure cellular survival. In Bacteria, a variety of alternative sigma factors recognize and bind promoter sequences in response to changing environmental conditions and target the transcription machinery towards genes whose products are required to survive the given circumstances (Paget, 2015). Several helix-turn-helix domain containing transcription factors were described in Archaea as transcription regulators of e.g. the central carbon- and energy- as well as amino acid metabolism (Peeters \& Charlier, 2010). The crenarchaeon Sulfolobus acidocaldarius produces three cell surface appendages that are homologous to bacterial type-IV-pili (T4P). In archaea, T4P have functions such as surface attachment, biofilm formation, cell aggregation and motility (Albers \& Meyer, 2011; Albers \& Pohlschroder, 2009; Makarova, Koonin, \& Albers, 2016; Pohlschroder \& Albers, 2011). The archaeal adhesive pilus (Aap)-pilus is the most abundant cell surface structure in exponentially growing $S$. acidocaldarius. Aap-pili are required for adhesion to surfaces and are involved in biofilm formation (Henche et al., 2012b,a). Other surface appendages are produced in response to environmental changes, e.g. the $\underline{\mathrm{UV}}$-inducible pili system (Ups), which is induced upon UVirradiation and other stress factors that promote DNA-double strand breaks. Ups-pili are used to form cellular aggregates that allow DNA exchange between cells via the Ced System.

S. acidocaldarius can thereby repair (UV-induced) double strand breaks via homologous recombination (Fröls et al 2008; van Wolferen et al., 2013; van Wolferen et al., 2016). Apart from that, $S$. acidocaldarius produces its motility structure, the archaellum, in response to nutrient limitation (Lassak et al., 2012). The archaellum of $S$. acidocaldarius consists of seven proteins (FlaB, FlaX, FlaG, FlaF, FlaH, FlaI, and FlaJ) that are encoded in an operon whose transcription is controlled by two promoters (pflaB and pflaX) (Lassak et al., 2012). Expression of the archaellum is tightly regulated by a complex network of positive and negative regulators and phosphorylation by various protein kinases plays a fundamental role in the regulatory process (Hoffmann et al., 2016; Haurat et al., 2017; Li et al., 2017). Especially the promoter upstream of the gene encoding the archaellum filament protein FlaB is strongly induced upon 
62 nutrient depletion (Lassak et al., 2012; Lassak et al., 2013). Under nutrient limiting conditions, 63 the membrane bound transcription regulator ArnR is required for the induction of archaellum 64 expression. While ArnR is conserved in Sulfolobales and Desulfurococcales, the ArnR paralog 65 ArnR1 is exclusively found in S. acidocaldarius (Lassak et al., 2013). ArnR and ArnR1 are two 66 one-component systems - the predominant class of regulatory systems in archaea and bacteria 67 (Ulrich, Koonin \& Zhulin, 2005). They encompass an almost identical N-terminal helix-turn68 helix (HTH) domain; a putative HAMP (present in histidine kinases, adenyl cyclases, methyl69 accepting proteins and phosphatases) and sensing domain presumably involved in sensing and 70 transducing a starvation-related signal; and two C-terminal transmembrane domains (Fig. 1)

71 (Lassak et al., 2013).

72 The deletion of either of the two regulators leads to reduced cell motility under nutrient 73 depletion, with the deletion of $\operatorname{arnR}$ causing a stronger reduction than the delion of arnR1(Lassak et al., 2013)(Lassak et al., 2013)(Lassak et al., 2013)(Lassak et al., 2013)(Lassak et al., 2013). The simultaneous deletion of both regulators leads to non-motile cells (Lassak et al., 2013). Conditions under which expression of $\operatorname{arnRl}$ is induced are unknown, whereas transcription of $a r n R$ increases upon nutrient-limitation. Both proteins presumably target the flaB 78 79 80 promoter, which harbors two conserved cis-regulatory elements called ArnR box-1 and -2. It was shown that deletion of both boxes abolishes and mutation of box-2 strongly decreases flaB promoter activity (Lassak et al., 2013).

Recently, the deletion of the core component of the archaeal adhesive pilus (Aap) was found to result in upregulation of the archaellum operon and hyperarchaellated cells (Henche et al., 2012a). Based on these findings, cross-regulation between the archaellum and Aap-pili was proposed, but the underlying system was not identified so far. Here, we set out to study the regulatory function of the two one-component systems ArnR and ArnR1 on T4P surface structures of $S$. acidocaldarius. Purification strategies for both membrane proteins in full-length were developed and their oligomeric state was assessed. We analyzed if ArnR and ArnR1 are targets of the eukaryotic-like protein kinases ArnC and ArnD, which are well-known archaellum regulators (Hoffmann et al., 2016). Lastly, an in vitro assay was established to assess their binding affinities to different T4P promoters and qRT-PCR was performed to confirm the results in vivo. To our knowledge, this is the first study of archaeal membrane-bound transcription regulators. 


\section{Materials \& Methods}

94

95

96

97

98

100

101

102

103

104

105

106

107

108

109

110

111

112

113

114

115

116

117

118

119

120

121

122

123

124

125

\section{S. acidocaldarius strains, plasmids and growth conditions}

All strains used in this study are described in Table S1. Strains were grown essentially as described, using basal Brock medium ( $\mathrm{pH} 3.5$ ) supplemented with $0.1 \% \mathrm{NZ}$-amine, $0.2 \%$ sucrose and $10 \mu \mathrm{g} / \mathrm{ml}$ Uracil (Wagner et al., 2012). Plasmids and their creation are described in Table S2. Primers are listed in Table S3.

\section{E.coli strains, plasmids and growth conditions}

All E. coli strains used in this study are described in Table S1. All strains were grown in LB medium supplemented with the respective antibiotics. Plasmids were generated as described in Table S2 using primers described in Table S3.

\section{SDS-PAGE and Western Blot analysis}

Total membranes or purified protein samples were supplemented with 5x SDS-loading buffer (10 \% (w/v) SDS, 300 mM Tris/HCl pH 6.8, 500 mM DTT, 50 \% (v/v) Glycerol, 0.04 \% (w/v) bromphenole blue) and subjected to SDS-PAGE analysis according to the method of Laemmli using $11 \%$ gels. For Western-Blot analysis, proteins were transferred onto PVDF membranes (Roche diagnostics) using the semi-dry method. His-HRP antibody (Abcam) diluted 1:10.000 in PBST was used to detect ArnR and ArnR1. PBST was prepared by diluting a $10 \mathrm{x}$ PBS stock (composition: $580 \mathrm{mMNa}_{2} \mathrm{HPO}_{4} \times 2 \mathrm{H}_{2} \mathrm{O}, 170 \mathrm{mM} \mathrm{NaH}_{2} \mathrm{Po}_{4} \times \mathrm{H}_{2} \mathrm{O}, 680 \mathrm{mM} \mathrm{NaCl}, 0.05 \%$ Tween $20 \mathrm{pH} 7.3$ ) to $1 \mathrm{x}$ PBS using distilled $\mathrm{H}_{2} \mathrm{O}$ and $0.05 \%$ Tween 20 was added. Chemiluminescent signals were detected as described (Hoffmann et al., 2016).

\section{Expression and purification of ArnR and ArnR1}

Overexpression of ArnR from pSVA2543 and ArnR1 from pSVA2538 was performed essentially as described (Studier, 2014) using the E. coli BL21 (DE3) derivative strain E. coliOverExpress(tm)C43(DE3) (Lucigen). Cells were grown for approximately 48 hours to $\mathrm{OD}_{600}$ of 12. Membranes were isolated essentially as described (Bischof et al., 2016), using buffer A (20 mM Tris/HCl, $\mathrm{pH} \mathrm{8,300} \mathrm{mM} \mathrm{NaCl).} \mathrm{Solubilization} \mathrm{was} \mathrm{performed} \mathrm{for} 2 \mathrm{~h}$ at $4{ }^{\circ} \mathrm{C}$, using $5 \mathrm{mg} / \mathrm{ml}$ total membranes in solubilization buffer (buffer A supplemented with $10 \mathrm{mM}$ Imidazole, $2 \%$-Dodecyl- $\beta$-d-maltopyranoside (DDM) (Glycon)). Solubilized protein was isolated from residual membranes using ultracentrifugation $\left(400,000 \times g, 4{ }^{\circ} \mathrm{C}, 1 \mathrm{~h}\right)$ and purified 
126 using $1 \mathrm{ml}$ of His-Select nickel affinity gel resin (Sigma) equilibrated in solubilization buffer.

127 Solubilized protein was applied to the resin and the flow-through was collected. After washing of 128 the column with $5 \times 1 \mathrm{ml}$ of wash buffer (buffer A supplemented with $20 \mathrm{mM}$ Imidazol, $0.5 \%$ $129 \operatorname{DDM}($ Glycon)), bound target protein was eluted using 5 x $500 \mu \mathrm{l}$ buffer A supplemented with $130 \quad 0.03 \%$ DDM and $150 \mathrm{mM}$ Imidazole. Eluted ArnR protein was desalted to buffer A 131 supplemented with $0.03 \%$ DDM using a PD10 column (GE Healthcare), according to the 132 manufacturers protocol. Eluted ArnR1 protein was further purified using a Heparin-HP column 133 (GE Healthcare) on an Äkta purifier system (GE Healthcare). Therefore, fractions containing 134 ArnR1 were diluted to $20 \mathrm{mM} \mathrm{NaCl}$ in buffer A supplemented with $0.03 \%$ DDM and loaded on 135 a $5 \mathrm{ml} \mathrm{HisTrap} \mathrm{HP}$ at $1 \mathrm{ml} / \mathrm{min}$ flow rate. After washing of the column with $20 \mathrm{mM} \mathrm{Tris} / \mathrm{HCl} \mathrm{pH}$ $1368,20 \mathrm{mM} \mathrm{NaCl}, 0.03 \%$ DDM for at least 5 column volumes, ArnR1 was eluted in $2 \mathrm{ml}$ fractions 137 using $20 \mathrm{mM}$ Tris/HCl, pH 8, $500 \mathrm{mM} \mathrm{NaCl,} \mathrm{0.03 \%} \mathrm{DDM.} \mathrm{ArnR} \mathrm{as} \mathrm{well} \mathrm{as} \mathrm{ArnR1} \mathrm{were}$ 138 concentrated using ultrafiltration in a $100 \mathrm{kDa}$ cut-off Amicon (Merck Millipore). Protein 139 concentration was determined using BCA assay (Serva), according to the manufacturer's 140 protocol. The Analysis of the oligomeric state of purified ArnR and ArnR1 was performed using 141 Blue-Native PAGE analyses as described (Claeys, Geering \& Meyer, 2005) using NativeMark ${ }^{\mathrm{TM}}$ 142 unstained protein standards (Life Technologies, Inc.).

143

144 In vitro phosphorylation assays

145 In vitro phosphorylation assays of ArnR and ArnR1 with $\gamma\left[{ }^{32} \mathrm{P}\right]-\mathrm{ATP}$ (Hartmann Analytic) were 146 performed as described (20). The reaction buffer contained $20 \mathrm{mM}$ Tris/ $\mathrm{HCl} \mathrm{pH} \mathrm{8,} 150 \mathrm{mM}$ $147 \mathrm{NaCl}$. In a total final volume of $15 \mu \mathrm{l}, 2 \mu \mathrm{M}$ kinase and $3 \mu \mathrm{M}$ ArnR or ArnR1 were mixed and $1480.8 \mathrm{mM}$ non-radioactive ATP and $0.3 \mathrm{mM} \gamma\left[{ }^{32} \mathrm{P}\right]$-ATP were added to the samples.

149 To show that phosphorylation of the kinases was specific and further show that ArnR and ArnR1 150 do not possess auto-phosphorylation activity negative control samples were taken along, that 151 contained only the respective protein and the ATP mixture. In another negative control, the 152 kinases were incubated in the absence of ATP and ArnR and ArnR1. After incubation of all 153 samples at $55^{\circ} \mathrm{C}$ for $10 \mathrm{~min}, 5 \mathrm{x}$ SDS-loading dye was added to a final concentration of 1 times 154 to stop the reaction. Proteins were separated on $11 \%$ SDS gels and exposed on a phosphostorage 155 screen (Molecular Dynamics) overnight. Screens were scanned using Typhoon FLA 7000, Ge 
156 Healthcare. Thee independent experiments were performed and a representative phosphoimage is 157 shown.

158

159

160

161

162

163

164

165

166

167

168

169

170

171

172

173

174

175

176

177

178

179

180

181

182

183

184

185

186

187

\section{Microscale thermophoresis}

For MST measurements, double stranded AlexaFluor647-labelled DNA was generated by annealing two primers (Table S3). Therefore, primers were mixed in equal amounts ( $5 \mathrm{mM}$ final concentration) in $20 \mathrm{mM}$ Tris/ $\mathrm{HCl} \mathrm{pH} 8,200 \mathrm{mM} \mathrm{NaCl}$ and $0.05 \%(\mathrm{w} / \mathrm{v})$ DDM, heated to $90{ }^{\circ} \mathrm{C}$ and then cooled to $20^{\circ} \mathrm{C}$ in steps of $2^{\circ} \mathrm{C} / 10 \mathrm{sec}$ and annealing was monitored by analyzing primers before and after annealing on $15 \%$ TBE Gels. To determine the binding affinity of ArnR, $2.5 \mathrm{nM}$ labeled, double-stranded DNA was titrated with increasing concentrations of ArnR $(0.156-18 \mu \mathrm{M})$. The measurements were performed at $24^{\circ} \mathrm{C}$ and $80 \%$ LED power. Samples were incubated for $10 \mathrm{~min}$ before measurements and centrifuged at $16,000 \mathrm{rpm}$ in a table top centrifuge (Eppendorf). The laser on and off times were adjusted to $25 \mathrm{~s}$ and $5 \mathrm{~s}$, respectively. Measurements were performed on a NanoTemper Monolith NT.115 instrument in hydrophilic-treated capillaries, and analyzed using NT analysis software version 1.4.27 (NanoTemper Technologies $\mathrm{GmbH}$ ). The data of two independent experiments performed in duplicate were used to calculate binding affinities. Therefore, fluorescence was normalized $(\Delta F)$ by subtracting the lowest measured fluorescence value determined within each experiment from all measured Fluorescence values. Obtained curves were fitted using non-linear regression, with one site specific binding according to $\left(\mathrm{y}=\mathrm{F}_{\max } * \mathrm{X} /\left(\mathrm{K}_{\mathrm{D}}+\mathrm{X}\right)\right)$.

\section{qRT-PCR}

Total RNA samples were isolated from shaking cultures before $(0 \mathrm{~h})$ and after $2 \mathrm{~h}$ of starvation. Samples were isolated as described (Lassak et al., 2012). TRIzol reagent (Invitrogen) was used for total RNA isolation following manufacturer's instructions. Digestion of gDNA and preparation of cDNA was performed using Quantinova Reverse Transcription Kit (Qiagen), according to the manufacturer's protocol. The gDNA removal was performed for 3 min, and the Reverse Transcription reaction for $7 \mathrm{~min}$. Quantitative reverse transcriptase (qRT-PCR) analysis of aapF and ups Xwas performed as described (Haurat et al., 2017) using Magnetic Induction Cycler (Bio Molecular Systems), 2x qPCRBIOSyGreen Mix Lo-ROX (Nippon genetics) according to the manufacturer's protocol, in combination with primers listed in Table S3. Three biological replicates and two technical replicates were assayed. Gene expression of aapF and 
$188 u p s X$ was normalized to their expression at timepoint $0 \mathrm{~h}$ (before starvation) and depicted in 189 log2-fold change. Alcohol dehydrogenase (saci_1690) was used as housekeeping gene as 190 transcript levels of this gene are not affected by nutrient limiting conditions (Bischof \& et al, 191 2018).

192

193

194

195

196

197

198

199

200

201

202

203

204

205

206

207

208

209

210

211

\section{Results}

\section{ArnR and ArnR1 form oligomeric structures}

To characterize ArnR and ArnR1, both regulators were heterologously expressed in Escherichia coli and purified to homogeneity (Fig. 2). To optimize translation rates for the respective proteins, ArnR and ArnR1 encoding genes were codon-optimized for E. coli (Table S4) and synthetically manufactured (Genscript, USA). Codon optimized arnR and arnRl were expressed with an N-terminal His10-tag under control of an arabinose inducible promoter (Geertsma \& Dutzler, 2011; Geertsma, 2014) in E. coliOverExpress C43(DE3) cells using autoinduction medium (Studier, 2014).

ArnR and ArnR1 were solely detected in the E. coli membrane fraction (Fig.2A), which was used further for protein purification via Nickel-affinity chromatography coupled to desalting of eluted protein samples (Fig. 2A, middle). The identity of ArnR and ArnR1 was confirmed by immunoblot analysis using His-specific antibodies (Fig 2B). To determine the oligomeric state of purified ArnR and ArnR1, Blue-Native PAGE analysis was performed (Fig 2C). ArnR and ArnR1 formed diverse multimeric species from monomeric to dodecameric (Fig 2C). This is in agreement with the observation that transcription factors adopt homo-dimeric or multimeric states in their active conformation (Wolberger, 1999). The formation of various oligomeric species moreover showed that both regulators are stable and correctly folded after purification.

212

213 ArnR and ArnR1 are phosphorylated by the Serine/Threonine kinase ArnC

214 Expression and presumably activity of the archaellum is regulated by reversible protein 215 phosphorylation. The two eukaryotic protein kinases ArnC and ArnD phosphorylate multiple 216 serine and threonine residues of the archaellum repressor ArnB (Hoffmann et al., 2016). ArnC 217 (but not ArnD) further phosphorylates ArnA, which is thought to be essential for the interaction 218 and activity of ArnA and ArnB (Reimann et al., 2012; Hoffmann et al., 2016). Phosphoproteome 
219 analysis revealed phosphorylation of Tyr217 and Thr222 in S. acidocaldarius ArnR1 and two 220 neighboring tyrosine residues in the HAMP-domain (Tyr154 and Tyr155) of S. solfataricus 221 ArnR (Esser et al., 2012; Reimann et al., 2013) (Sso_ArnR, Fig 3A). Therefore, phosphorylation 222 assays were performed next to analyze if ArnR and ArnR1 are phosphorylated in vitro. Given the 223 fact that the protein kinases ArnC and ArnD are involved in archaellum regulation (Hoffmann et 224 al., 2016), they were incubated with ArnR or ArnR1 in the presence of radioactively labelled $225 \gamma^{32} \mathrm{P}-\mathrm{ATP}$ and phosphotransfer from the kinases to the regulators was monitored. Signals 226 corresponding to auto-phosphorylation of ArnC (Fig. 3B, lane 4) and ArnD (Fig. 3C, lane 4) was 227 obtained. Strikingly, phosphotransfer was observed from ArnC to both ArnR andArnR1 (Fig. 3B, 228 second to last and last lane), while no phosphotransfer to ArnR or ArnR1 was observed from 229 ArnD (Fig. 3C, second to last and last lane). In addition, two distinct bands were obtained for 230 phosphorylated ArnR and ArnR1 that might correspond to phosphorylated monomeric and 231 dimeric species of the proteins (Fig. 3B, second to last and last lane), indicating that the 232 multimerisation observed on BN-PAGE (Fig. 2B) might have a functional relevance.

234 ArnR and ArnR1 bind to the flaB promoter

235 To understand their function as transcriptional activators of the archaellum operon, binding of 236 full-length ArnR and ArnR1 to different flaB promoter sequences was investigated. It was 237 recently described that the $f l a B$ promoter $(\mathrm{p} f l a B$ ) harbors two 15 bp cis-regulatory elements 238 (ArnR box-1 and ArnR box-2), which are inverted repeats with the consensus sequence TCGAC239 (N)5-GTCGA (Lassak et al., 2013) (Fig. 4A). To characterize the binding of ArnR and ArnR1 to 240 the $f l a B$ promoter, three different Alexa Fluor 647 labeled promoter fragments were generated 241 and subjected to microscale thermophoresis (MST) experiments in the presence of increasing 242 amounts of detergent-purified ArnR or ArnR1. A $41 \mathrm{bp}$ fragment containing both ArnR boxes $243\left(\mathrm{p} f l a B^{41}\right)$ as well as a fragment containing either ArnR box-1 or ArnR box-2 were used (Fig. 4A). 244 With increasing concentrations of ArnR (Fig. 4B, left graph) or ArnR1 (Fig. 4B, right graph), 245 binding to $\mathrm{p} f l a B^{41}$ was detected as was visualized by increasing fluorescence signals (Kd ArnR: $2464.6 \mu \mathrm{M}, \mathrm{Kd}$ ArnR1: $3.31 \mu \mathrm{M}$ ) (Fig. 4B). In experiments with flaB promoter fragments containing 247 only ArnR box-1 or box-2, an increase in fluorescence signals was not observed (Fig. 4B), 248 demonstrating that for efficient binding both boxes are required. 
251 A cross-regulation between Aap-pili and the archaellum was proposed recently, as a deletion

252 mutant of the central membrane protein coding gene aapF of the Aap-system lead to hypermotile 253 cells (Henche et al., 2012a). To analyze if apart from the archaellum ArnR and ArnR1 regulate 254 the Aap- or the Ups-system of $S$. acidocaldarius, fragments of the aapF and ups $X$ promoter 255 sequences were subjected to MST analysis (Fig. 5A). Strikingly, ArnR bound to paapF (Kd 1.5 $256 \mu \mathrm{M})$ and pups $X(\mathrm{Kd} 1.78 \mu \mathrm{M})$ (Fig. 5B, left graph), whereas ArnR1 did not (Fig. 5B, right 257 graph). The promoter fragment of saci_2122 (encoding a putative sugar binding protein) was 258 used as negative control. Neither ArnR nor ArnR1 showed binding to pSaci_2122, supporting 259 the idea that ArnR and ArnR1 exclusively regulate T4P related promoters. Taken together these 260 results suggest that ArnR is involved in regulation of the archaellum, the Aap- and Ups-pilus of 261 S. acidocaldarius while ArnR1 exclusively exerts its function in the archaellum.

262 Subsequently, we aimed to understand if there is an effect of phosphorylation of ArnR and 263 ArnR1 on binding to $\mathrm{p} f l a B, \mathrm{p} f l a B$ ArnR box-1, pflaB ArnR box-2, pups $X$ and paapF. Therefore, 264 ArnR and ArnR1 were incubated with ArnC and subjected to MST analysis. However, ArnR as 265 well as ArnR1 were aggregating during the experiment, which hindered further analysis.

266

\section{The deletion of arnR and $a r n R 1$ affects transcription of aapF and ups $X$}

268

It was recently shown, that the deletion of $\operatorname{arn} R$ and $\operatorname{arn} R 1$ negatively affects the transcription

269 rate of flaB and reduces motility of cells (Lassak et al., 2013). Since apart from binding to $\mathrm{p} f l a B$ ArnR also bound to paapF and pups $X$ in our MST analysis, the effect of arnR deletion on aapF and ups $X$ levels was investigated in vivo. Up to now, the only known condition under which

272 transcription of $\operatorname{arnR}$ is induced is nutrient depletion (Lassak et al., 2013). Therefore, a deletion mutant of arnR (S. acidocaldarius MW328) was subjected to nutrient depletion for $2 \mathrm{~h}$ and levels of $a a p F$ and ups $X$ transcription were monitored relative to their transcription before starvation.

275 The deletion mutant of arnRl was also assayed to analyze whether the deletion of arnRl affects

276 transcription levels of aapF and ups $X$ even tough binding to their respective promoter regions 277 was not detected in vitro.

278 As depicted in Figure 6, a $\log 2$ four-fold induction of aapF transcription after $2 \mathrm{~h}$ of nutrient 279 limitation was detected in S. acidocaldarius MW001 (wild type) cells. Remarkably, aapF 280 transcription was $\log 2$ four-fold downregulated in the $\operatorname{arn} R$ deletion mutant and also significantly $281(\mathrm{p}>0.05)$ reduced in the arnR1 deletion strain (Fig. 6). In S. acidocaldarius MW001 (wild type) a 
$282 \log 2$ two-fold induction of ups $X$ was detected upon starvation, and the deletion of $\operatorname{arn} R$ 283 (S. acidocaldarius MW328) led to a $\log 2$ four-fold downregulation of ups $X$ (Fig. 6). No 284 significant ( $>0.05$ ) change of ups $X$ transcript levels was found in the arnR1 deletion mutant 285 (Fig. 6). This confirms our MST binding assays and shows that ArnR is involved in the 286 regulation of the aap and ups operons. Further, as identified by qRT-PCR ArnR1 is involved in 287 the regulation of the aap operon. 


\section{Discussion}

290 We investigated the function of ArnR and ArnR1 as transcription regulators of the archaellum, 291 Aap and Ups pili system of $S$. acidocaldarius. Both proteins were purified to homogeneity and 292 characterized in vitro. This is, to the best of our knowledge, the first biochemical analysis of 293 membrane-bound transcription factors in archaea.

294 A well-studied group of archaeal transcription regulators are the helix-turn-helix domain 295 containing Lrp-type transcriptional regulators. These regulate the amino acid metabolism and 296 therefore bind small receptor molecules with their C-terminal RAM-domain (Regulation of 297 Amino acid Metabolism (Peeters \& Charlier, 2010). They are functional in an oligomeric state 298 and the minimal unit required for the interaction with the DNA is the dimeric species while 299 higher multimers are often found in solution (Leonard et al., 2001; Yokoyama et al., 2006; 300 Peeters et al., 2007, 2009). Dimeric Lrp-type regulators in archaea recognize 13-17 bp DNA 301 binding sites that contain an imperfect inverted repeat with an AT-rich center (Ouhammouch \& 302 Geiduschek, 2001, 2005; Peeters et al., 2007; Peeters \& Charlier, 2010), as was also found in the

303 flaB promoter sequence (Lassak et al., 2013). Lrp-type transcription regulators are well-known to 304 form different oligomeric species. Based on these findings, a regulatory mechanism in which the 305 different regulators regulate a variety of genes by varying their assembly form and also

306

307 308

309

310

311

312 different promoters.

313 In the euryarchaeon Methanococcus maripaludis, the transcriptional activator EarA, which does 314 315 316 317 binding sites from the fla promoter (Ding et al., 2016). As mentioned earlier, the proposed target 318 319 box-2) and the lack of both boxes as well as mutation of box-2 significantly reduces flaB combining other transcription regulators into the assembly forms in response to environmental changes was proposed (Koike et al., 2004). The transition between different forms is thought to determine their binding specificity and ligands are thought to stabilize different assemblies and hereby allow the organism to adjust its overall transcriptome to environmental changes (Koike et al., 2004). We found oligomeric assemblies of ArnR and ArnR1 in this study. Therefore, such a mechanism might also underlie ArnR and ArnR1 function and allow regulatory effects on not share homology with ArnR, promotes fla operon transcription by binding to a 6 bp consensus sequence (TACATA) that is present four times in the fla operon (Ding et al., 2016).

316 Transcription of the fla operon in M. maripaludis is abolished upon elimination of the four EarA 18 of ArnR and ArnR1 are two inverted repeats in the flaB promoter sequence (ArnR box-1 and 
320 promoter activity (Lassak et al., 2013). In the in vitro studies performed here, ArnR and ArnR1

321 could only bind to the DNA molecule when both boxes were present. Furthermore, ArnR bound

322 to promoter sequences of aapF and ups $X$. Both fragments did not harbor the inverted repeats.

323 Since neither ArnR nor ArnR1 bound to the promoter sequence of the non-T4P related gene

324 saci_2122 (encodes a putative sugar binding protein) it is tempting to speculate that ArnR and

325 ArnR1 are specifically regulating T4P surface structures of $S$. acidocaldarius.

326 The findings obtained from MST experiments were confirmed in vivo using qRT-PCR. It was

327 recently shown, that the deletion of $\operatorname{arnR}$ leads to a decrease of $f l a B$ transcript levels of

328 around $80 \%$ (Lassak et al., 2013) in nutrient depleted cells. In addition, we observed here a log2

3298 -fold decrease of aapF and ups $X$ transcript levels in the arnR deletion variant during nutrient

330 starvation as compared to wild-type cells. Thus, ArnR functions as transcriptional activator not

331 only of the archaellum but is also involved in cross-regulation of the Aap and Ups pili system of

332 S. acidocaldarius during nutrient depletion. Apart from that, a decrease of aap $F$ but not of ups $X$

333 transcript levels was observed in the $\operatorname{arnRl}$ deletion mutant under starvation conditions,

334 indicating a different regulatory function of ArnR1. It is likely that ArnR1 also regulates the flaB

335 and aapF promoters under conditions other than starvation as transcription of arnRl is not

336 induced by starvation (Lassak et al., 2013). For instance, in Methanocaldococcus jannaschii

337 hydrogen limitation promotes archaella synthesis while in M. maripaludis a decrease of

338 archaellum gene transcription in response to leucine starvation was described(Mukhopadhyay,

339 Johnson \& Wolfe, 2000; Hendrickson et al., 2008). It is known that under different stress

340 sources, such as nutrient or phosphate limitation or osmotic and $\mathrm{pH}$ stress, S. acidocaldarius

341 regulates gene transcription and translation according to its needs (Osorio \& Jerez, 1996; Lassak

342 et al., 2012, 2013; Buetti-Dinh et al., 2016). To date, neither $\operatorname{arnR}$ nor arnRl were regulated

343 under conditions other than starvation (e.g pH and salt-stress,(Buetti-Dinh et al., 2016)), raising

344 the question of which membrane-related signal both regulators sense and transduce.

345 A connection between the archaellum and T4P was described for M. maripaludis, where

346 archaella together with pili are important for binding to abiotic surfaces (Jarrell et al., 2011). .

347 S. acidocaldarius is by now the only identified species that possesses the Aap-pilus, which is the

348 most abundant surface structure during exponential growth and majorly important during biofilm

349 formation, where the archaellum only plays a role in the release of cells from the biofilm

350 (Henche et al., 2012b). An actual cross-regulation of the archaellum, Aap- and Ups pilus was 
351 proposed as the deletion of the membrane spanning core component of the Aap-pilus promoted

352 archaella formation and upregulation of the archaellum operon (Henche et al., 2012b).

353 Recently, a high number of phosphorylated proteins was detected in S. acidocaldarius and

354 S. solfataricus, including ArnR and ArnR1 (Esser et al., 2012; Reimann et al., 2013). In this

355 study, we observed phosphorylation of both regulators by the eukaryotic-like protein kinase

356 ArnC (but not by ArnD). Phosphorylation is well-known post-translational modification that is

357 crucially involved in archaeal signal transduction (Esser et al., 2016). ArnR and ArnR1 are

358 phosphorylated in vivo (Esser et al., 2012; Reimann et al., 2013) and, as shown in this study,

359 both proteins are phosphorylated by the serine/threonine eukaryotic protein kinase ArnC. Thus,

360 apart from the two Tyr residues identified in the $S$. solfataricus ArnR homolog Saci_ArnR

361 potentially harbors additional Ser/Thr residues that are post-translationally phosphorylated.

362 Reversible protein phosphorylation is known to regulate the activity of archaellum regulators

363 (Hoffmann et al., 2016; Haurat et al., 2017; Li et al., 2017). Therefore, it is tempting to speculate

364 that ArnR and ArnR1 are also regulated by phosphorylation. Potentially, the phosphorylation

365 status of ArnR and ArnR1 might regulate their promoter affinities to different T4P promoter

366 sequence to regulate the expression of the surface structures. Unfortunately, DNA-binding

367 analysis (MST) with phosphorylated ArnR and ArnR1 were impaired by protein aggregation .

368 ArnR and ArnR1 possess a sensing-domain in close proximity to their transmembrane anchors.

369 Therefore, a membrane-associated stimulus was proposed to activate ArnR and ArnR1 (Lassak

370 et al., 2013). It was proposed that a membrane-bound sensor kinase, ArnS, paradoxically inhibits

$371 \operatorname{arnR}$ transcription while promoting ArnR translation (Haurat et al., 2017). In general,

372 transcriptional activators interact with the basal transcription factors (TBP and TFB in archaea)

373 to enhance gene transcription. However, a concentration-dependent dual function as activator

374 and repressor was also described for transcriptional regulators (Peeters, Peixeiro \& Sezonov,

375 2013). ArnR and ArnR1 are activators of motility, however it cannot be excluded that they act as

376 transcriptional repressors on other T4P structures and under other conditions than starvation. A

377 current model of the archaellum regulatory network is shown in Figure 7. In summary, this study

378 provides further evidence for cross-regulation of the archaeal motility structure and other T4P

379 surface structures in S. acidocaldarius.

380

381

Conclusions 
382

383 Our results show that ArnR and ArnR1 can be purified to homogeneity, and form multimers.

384

385

386

387

388

389

390

391

392

393

394

395

396

397

398

399

400

401

402

403

404

405

406

407

408

409

410

411

412

413

414

415

416

417

418

419

420

Both proteins are phosphorylated by ArnC, but not ArnD, and thus it appears like

phosphorylation is an additional regulatory level that is important for ArnR and ArnR1 function.

ArnR and ArnR1 require the presence of both Arn boxes of the flaB promoter as regulatory

elements to bind to the promoter region. Further, ArnR but not ArnR1 bound to paapF and

pups $X$, as was confirmed in vivo, where decreased aapF transcript levels were also detected in

the arnR1 deletion mutant. All in all, our data suggest that ArnR and ArnR1 are part of a

regulatory network, that tightly regulates the expression of type IV pilus surface structures of

S. acidocaldarius.

\section{Acknowledgements}

We thank Prof. Carola Hunte for giving access to Nanotemper Monolith NT.115 Instrument. We thank Marleen van Wolferen and Chris van der Does for critical reading of the manuscript.

\section{References}

Albers S-V., Meyer BH. 2011. The archaeal cell envelope. Nature reviews. Microbiology 9:414426. DOI: $10.1038 /$ nrmicro2576.

Albers S-V., Pohlschroder M. 2009. Diversity of archaeal type IV pilin-like structures. Extremophiles : life under extreme conditions 13:403-410. DOI: 10.1007/s00792-009-02417.

Bischof LF., Friedrich C., Harms A., Sogaard-Andersen L., van der Does C. 2016. The Type IV Pilus Assembly ATPase PilB of Myxococcus xanthus Interacts with the Inner Membrane Platform Protein PilC and the Nucleotide-binding Protein PilM. The Journal of biological chemistry 291:6946-6957. DOI: 10.1074/jbc.M115.701284.

Buetti-Dinh A., Dethlefsen O., Friedman R., Dopson M. 2016. Transcriptomic analysis reveals how a lack of potassium ions increases Sulfolobus acidocaldarius sensitivity to $\mathrm{pH}$ changes. Microbiology (United Kingdom) 162:1422-1434. DOI: 10.1099/mic.0.000314.

Claeys D., Geering KK., Meyer BJ. 2005. Two-dimensional Blue Native/sodium dodecyl sulfate gel electrophoresis for analysis of multimeric proteins in platelets. Electrophoresis 26:1189-1199. DOI: 10.1002/elps.200406196.

Ding Y., Nash J., Berezuk A., Khursigara CM., Langelaan DN., Smith SP., Jarrell KF. 2016. Identification of the first transcriptional activator of an archaellum operon in a euryarchaeon. Molecular Microbiology 102:54-70. DOI: 10.1111/mmi.13444.

Esser D., Hoffmann L., Pham TK., Bräsen C., Qiu W., Wright PC., Albers S-V., Siebers B. 2016. Protein phosphorylation and its role in archaeal signal transduction. FEMS microbiology reviews 40:625-47. DOI: 10.1093/femsre/fuw020. 
421 Esser D., Pham TK., Reimann J., Albers S V., Siebers B., Wright PC. 2012. Change of Carbon

422

423

424

425

426

427

428

429

430

431

432

433

434

435

436

437

438

439

440

441

442

443

444

445

446

447

448

449

450

451

452

453

454

455

456

457

458

459

460

461

462

463

464

465

466
Source Causes Dramatic E ff ects in the Phospho- Proteome of the Archaeon Sulfolobus solfataricus. journal of proteome research 11:4823-4833.

Fröls S., Ajon M., Wagner M., Teichmann D., Zolghadr B., Folea M., Boekema EJ., Driessen AJM., Schleper C., Albers SV. 2008. UV-inducible cellular aggregation of the hyperthermophilic archaeon Sulfolobus solfataricus is mediated by pili formation. Molecular Microbiology 70:938-952. DOI: 10.1111/j.1365-2958.2008.06459.x.

Geertsma ER. 2014. DNA Cloning and Assembly Methods. 1116:153-164. DOI: 10.1007/978-162703-764-8.

Geertsma ER., Dutzler R. 2011. A versatile and efficient high-throughput cloning tool for structural biology. Biochemistry 50:3272-3278. DOI: 10.1021/bi200178z.

Haurat MF., Figueiredo AS., Hoffmann L., Li L., Herr K., J. Wilson A., Beeby M., Schaber J., Albers SV. 2017. ArnS, a kinase involved in starvation-induced archaellum expression. Molecular Microbiology 103:181-194. DOI: 10.1111/mmi.13550.

Henche A-L., Ghosh A., Yu X., Jeske T., Egelman E., Albers S-V. 2012a. Structure and function of the adhesive type IV pilus of Sulfolobus acidocaldarius. 40:1301-1315. DOI:

10.1007/s10439-011-0452-9.Engineering.

Henche A-L., Koerdt A., Ghosh A., Albers S-V. 2012b. Influence of cell surface structures on crenarchaeal biofilm formation using a thermostable green fluorescent protein. Environmental Microbiology 14:779-793. DOI: 10.1111/j.1462-2920.2011.02638.x.

Hendrickson EL., Liu Y., Rosas-Sandoval G., Porat I., Soll D., Whitman WB., Leigh JA., Söll D., Whitman WB., Leigh JA. 2008. Global responses of Methanococcus maripaludis to specific nutrient limitations and growth rate. Journal of Bacteriology 190:2198-2205. DOI: 10.1128/JB.01805-07.

Hoffmann L., Schummer A., Reimann J., Haurat MF., Wilson AJ., Beeby M., Warscheid B., Albers S-V. 2016. Expanding the archaellum regulatory network - the eukaryotic protein kinases ArnC and ArnD influence motility of Sulfolobus acidocaldarius. MicrobiologyOpen:1-14. DOI: 10.1002/mbo3.414.

Jarrell KF., Stark M., Nair DB., Chong JPJ. 2011. Flagella and pili are both necessary for efficient attachment of Methanococcus maripaludis to surfaces. FEMS Microbiology Letters 319:44-50. DOI: 10.1111/j.1574-6968.2011.02264.x.

Koerdt A., Gödeke J., Berger J., Thormann KM., Albers SV. 2010. Crenarchaeal Biofilm Formation under Extreme Conditions. PLOS ONE 5. DOI: 10.1371/journal.pone.0014104.

Koike H., Ishijima SA., Clowney L., Suzuki M. 2004. The archaeal feast famine regulatory protein : Potential roles of its assembly forms for regulating transcription.

Koretke KK., Lupas AN., Warren P V., Rosenberg M., Brown JR. 2000. Evolution of twocomponent signal transduction. Molecular biology and evolution 17:1956-1970. DOI: 10.1093/oxfordjournals.molbev.a026297.

Lassak K., Neiner T., Ghosh A., Klingl A., Wirth R., Albers S-V. 2012. Molecular analysis of the crenarchaeal flagellum. Molecular microbiology 83:110-24. DOI: 10.1111/j.13652958.2011.07916.x.

Lassak K., Peeters E., Wróbel S., Albers S-V. 2013. The one-component system ArnR: a membrane-bound activator of the crenarchaeal archaellum. Molecular microbiology 88:125-39. DOI: 10.1111/mmi.12173.

Leonard PM., Smits SHJ., Sedelnikova SE., Brinkman AB., Vos WM De., Oost J Van Der., Rice DW., Rafferty JB. 2001. Crystal structure of the Lrp-like transcriptional regulator from the 
467

468

469

470

471

472

473

474

475

476

477

478

479

480

481

482

483

484

485

486

487

488

489

490

491

492

493

494

495

496

497

498

499

500

501

502

503

504

505

506

507

508

509

510

511

512

archaeon Pyrococcus furiosus. 20.

Li L., Banerjee A., Bischof LF., Ramadan Maklad H., Hoffmann L., Henche A-L., Veliz F., Bildl W., Schulte U., Orell A., Essen L-O., Peeters E., Albers S-V. 2017. Wing phosphorylation is a major functional determinant of the Lrs14-type biofilm and motility regulator AbfR1 in Sulfolobus acidocaldarius. Molecular Microbiology 105:777-793. DOI: 10.1111/mmi.13735.

Makarova KS., Koonin E V., Albers S-V. 2016. Diversity and Evolution of Type IV pili Systems in Archaea. Frontiers in microbiology 7:667. DOI: 10.3389/fmicb.2016.00667.

Mukhopadhyay B., Johnson EF., Wolfe RS. 2000. A novel pH2 control on the expression of flagella in the hyperthermophilic strictly hydrogenotrophic methanarchaeaon Methanococcus jannaschii. Proceedings of the National Academy of Sciences of the United States of America 97:11522-7. DOI: 10.1073/pnas.97.21.11522.

Osorio G., Jerez C a. 1996. Adaptive response of the archaeon Sulfolobus acidocaldarius BC65 to phosphate starvation. Microbiology 142:1531-1536. DOI: 10.1099/13500872-142-61531.

Ouhammouch M., Geiduschek EP. 2001. A thermostable platform for transcriptional regulation : the DNA-binding properties of two Lrp homologs from the hyperthermophilic archaeon Methanococcus jannaschii. 20.

Ouhammouch M., Geiduschek EP. 2005. An expanding family of archaeal transcriptional activators. Proceedings of the National Academy of Sciences of the United States of America 102:15423-8. DOI: 10.1073/pnas.0508043102.

Paget MS. 2015. Bacterial sigma factors and anti-sigma factors: Structure, function and distribution. Biomolecules 5:1245-1265. DOI: 10.3390/biom5031245.

Peeters E., Albers S-V., Vassart A., Driessen AJM., Charlier D. 2009. Ss-LrpB, a transcriptional regulator from Sulfolobus solfataricus, regulates a gene cluster with a pyruvate ferredoxin oxidoreductase-encoding operon and permease genes. Molecular microbiology 71:972-988. DOI: $10.1111 /$ j.1365-2958.2008.06578.x.

Peeters E., Charlier D. 2010. The Lrp family of transcription regulators in archaea. Archaea 2010. DOI: $10.1155 / 2010 / 750457$.

Peeters E., Peixeiro N., Sezonov G. 2013. Cis-regulatory logic in archaeal transcription. Biochemical Society transactions 41:326-31. DOI: 10.1042/BST20120312.

Peeters E., Wartel C., Maes D., Charlier D. 2007. Analysis of the DNA-binding sequence specificity of the archaeal transcriptional regulator Ss-LrpB from Sulfolobus solfataricus by systematic mutagenesis and high resolution contact probing. Nucleic acids research 35:623-633. DOI: 10.1093/nar/gk11095.

Pohlschroder M., Ghosh A., Tripepi M., Albers S-V. 2011. Archaeal type IV pilus-like structures--evolutionarily conserved prokaryotic surface organelles. Current opinion in microbiology 14:357-363. DOI: 10.1016/j.mib.2011.03.002.

Pohlschröder M., Hartmann E., Hand NJ., Dilks K., Haddad A. 2005. Diversity and Evolution of Protein Translocation. Annual Review of Microbiology 59:91-111. DOI: 10.1146/annurev.micro.59.030804.121353.

Pohlschroder M., Pfeiffer F., Schulze S., Halim MFA. 2018. Archaeal cell surface biogenesis. FEMS Microbiology Reviews 42:694-717. DOI: 10.1093/femsre/fuy027.

Reimann J., Esser D., Orell A., Amman F., Pham TK., Noirel J., Lindås A-C., Bernander R., Wright PC., Siebers B., Albers S-V. 2013. Archaeal Signal Transduction: Impact of Protein Phosphatase Deletions on Cell Size, Motility, and Energy Metabolism in Sulfolobus 
513

514

515

516

517

518

519

520

521

522

523

524

525

526

527

528

529

530

531

532

533

534

535

536

537

538

539

540

541

542

543 acidocaldarius. Molecular \& Cellular Proteomics 12:3908-3923. DOI: 10.1074/mcp.M113.027375.

Reimann J., Lassak K., Khadouma S., Ettema TJG., Yang N., Driessen AJM., Klingl A., Albers S-V. 2012. Regulation of archaella expression by the FHA and von Willebrand domaincontaining proteins ArnA and ArnB in Sulfolobus acidocaldarius. Molecular microbiology 86:24-36. DOI: 10.1111/j.1365-2958.2012.08186.x.

Studier FW. 2014. Stable Expression Clones and Auto-Induction for Protein Production in E. coli. In: Chen YW ed. Structural Genomics: General Applications. Totowa, NJ: Humana Press, 17-32. DOI: 10.1007/978-1-62703-691-7_2.

Ulrich LE., Koonin E V., Zhulin IB. 2005. One-component systems dominate signal transduction in prokaryotes. Trends in Microbiology 13:52-56. DOI: 10.1016/j.tim.2004.12.006.Onecomponent.

Wagner M., van Wolferen M., Wagner A., Lassak K., Meyer BH., Reimann J., Albers SV. 2012. Versatile genetic tool box for the crenarchaeote Sulfolobus acidocaldarius. Frontiers in Microbiology 3:1-12. DOI: 10.3389/fmicb.2012.00214.

Wolberger C. 1999. Multiprotein-DNA complexes in transcriptional regulation. Annual review of biophysics and biomolecular structure 28:29-56. DOI: 10.1146/annurev.biophys.28.1.29.

van Wolferen M., Ajon M., Driessen AJM., Albers SV. 2013. Molecular analysis of the UVinducible pili operon from Sulfolobus acidocaldarius. MicrobiologyOpen 2:928-937. DOI: 10.1002/mbo3.128.

van Wolferen M., Wagner A., van der Does C., Albers S-V. 2016. The archaeal Ced system imports DNA. Proceedings of the National Academy of Sciences 113:2496-2501. DOI: 10.1073/pnas. 1513740113.

Yokoyama K., Ishijima SA., Clowney L., Koike H., Aramaki H., Tanaka C., Makino K., Suzuki M. 2006. Feast/famine regulatory proteins (FFRPs): Escherichia coli Lrp, AsnC and related archaeal transcription factors. FEMS Microbiology Reviews 30:89-108. DOI: 10.1111/j.1574-6976.2005.00005.x.

Zolghadr B., Kling A., Koerdt A., Driessen AJM., Rachel R., Albers SV. 2010. Appendagemediated surface adherence of Sulfolobus solfataricus. Journal of Bacteriology. DOI: 10.1128/JB.01061-09. 


\section{Figure 1}

ArnR and ArnR1 share an overall domain organization.

Both proteins harbor an N-terminal helix-turn-helix ( $\mathrm{HTH}$, green)) domain, a putative HAMP (histidine kinases, adenyl cyclases, methyl-accepting proteins and phosphatases, blue) domain, a sensory domain (orange) and two C-terminal transmembrane domains (grey). Numbers correspond to the first and last amino acid of each domain. (Lassak et al 2013).

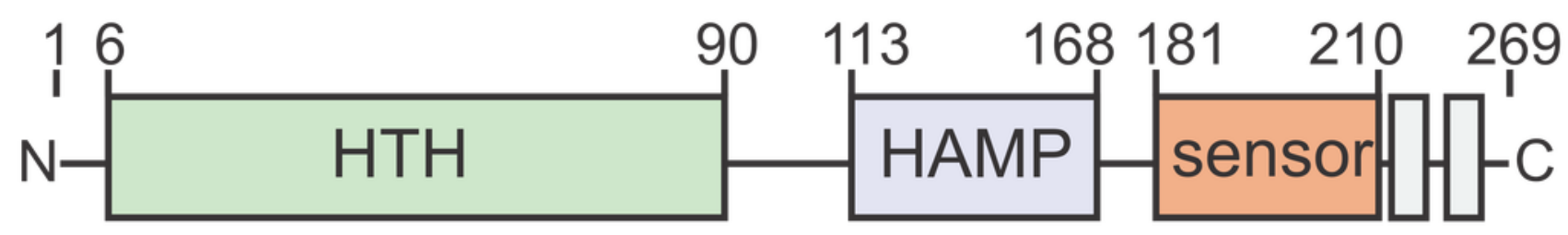




\section{Figure 2}

Purification of codon optimized ArnR and ArnR1 and formation of diverse multimeric species.

A. ArnR and ArnR1 were expressed in E.coliOverExpress C43(DE3). Membranes were isolated, and ArnR and ArnRlwere purified to homogeneity (A). Protein identity was confirmed using Western-Blot analysis using His-specific antibodies (B). Numbers represent masses of marker proteins in $\mathrm{kDa}$. Representative images of at least five purifications are shown. C.

Oligomerization of both regulators was analyzed using Blue-Native PAGE. Numbers on the right side represent mass of marker proteins in $\mathrm{kDa}$. Various multimeric species were formed by ArnR and ArnR1, as estimated by numbers on the left. Three independent experiments were performed and a representative image is shown.

A

B

C
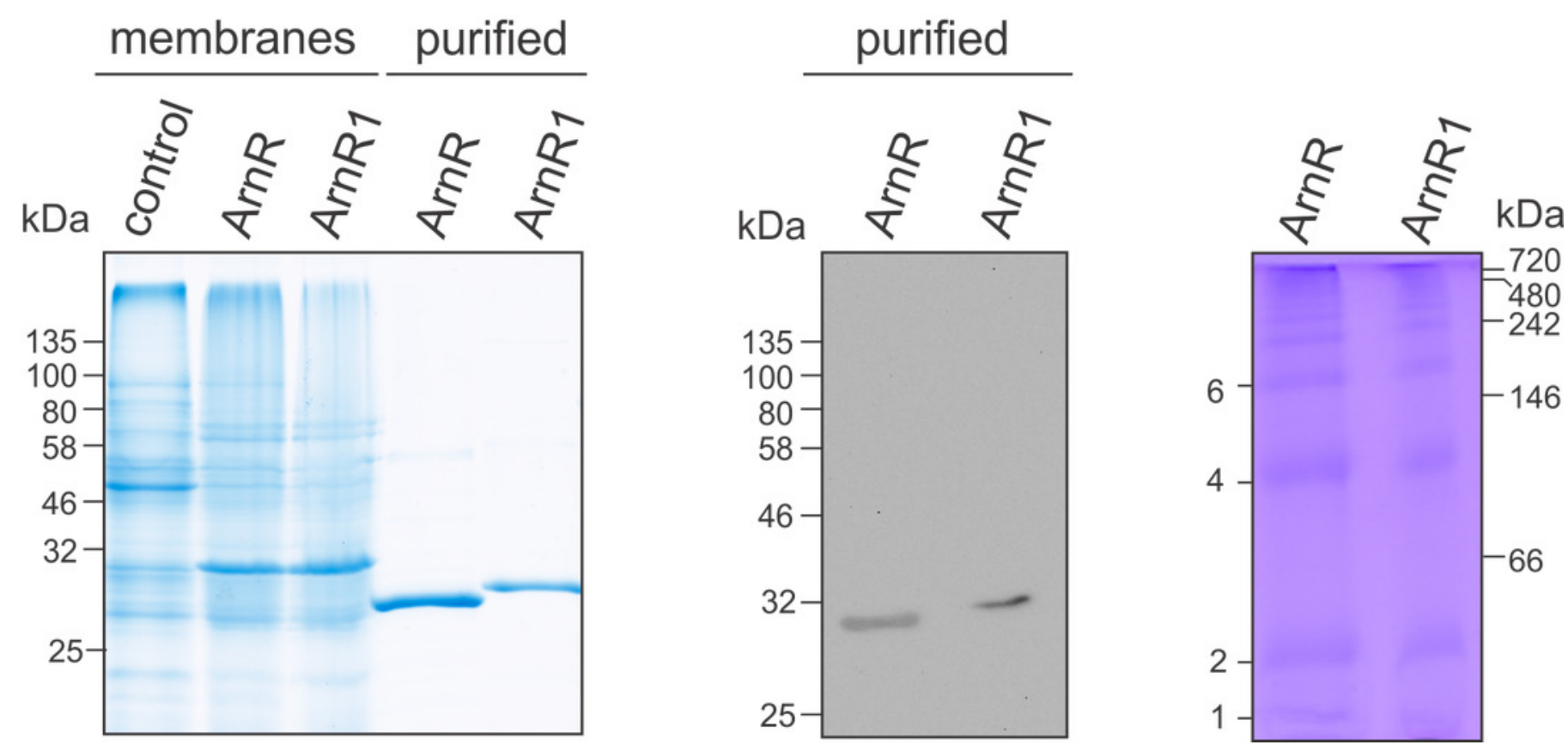


\section{Figure 3}

ArnR and ArnR1 are phosphorylated by ArnC.

A. Sequence alignment of S.solfataricus (Sso) ArnR and S.acidocaldarius (Saci) ArnR and ArnR1. Location of HTH (Helix-turn-Helix, green), HAMP (Histidine kinases, Adenyl cyclases, Methyl-accepting proteins and Phosphatases), sensor (orange) and transmembrane domain (blue) are depicted (Lassak et al., 2013). Saci_ArnR1 phosphorylation sites Tyr217 and Thr222 as identified in vivo are depicted in pink (Reimann et al., 2013) and Sso ArnR phosphorylation sites Tyr154 and Tyr155 are depicted in yellow (Esser et al., 2012). B and C. In vitro phosphorylation assay. $1 \mu \mathrm{M}$ ArnC (B) or ArnD (C) was incubated with $2 \mu \mathrm{M}$ ArnR or ArnR1 and $\mathrm{y}^{32}$-p-ATP and phosphotransfer from ArnC or ArnD to ArnR and ArnR1 was monitored, respectively. A representative phosphoimage of three independent experiments is shown. 
A

Sso_ArnR ---MSYNVF DVLRELDS IVDFARAKLQWDILFF INSRGPSS ISEIAEGTNNSKKAVIDAI

Saci_ArnR ---MTKSLFDVLKELDSLVDFSRAKLQWDILI I LATKGPSSTTEISQT INTSRKS I I DAI

Saci_ArnR1 MSSMNKRVFDILRELDSLVDFSRAKLQWDILI ILATKGPSSTTEISQT INTSRKS I IDAI

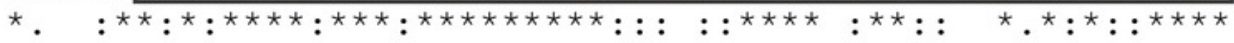

Sso_ArnR RKLVEKELIIKVKYDVYDLSEKGKQVLNKLNYFTSHTVSTQKSVDGD-NNVLSNNADNPS Saci_ArnR RKLVDKELVTKVKHDIYGLSDKGKELWNKIDSVLNIEVINGNNHKGQSKDEDILALENLS

Saci_ArnR1 RKLVDKELVTKVKGDIYGLSEKGEKLLESFDS IMS INVTDKP---DSS IESNS ISLTNIA

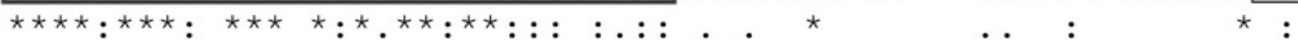

Sso_ArnR QNYYLLELIKMSLLNNGTLPIDKVSRELGISKQTVKYYLELFMRKKIFKKVNKKSLLGKS Saci_ArnR QYFYLINLSKMITINHDGLSLDKAARELGVSRQTLKYYLELFEEKKLFRVIGKRTHFKKN Saci_ArnR1 EYFYMLEILKMALLN-KOITIDKASHELGISKOTLKYYIETETENKLLKVVNOESVLGKS

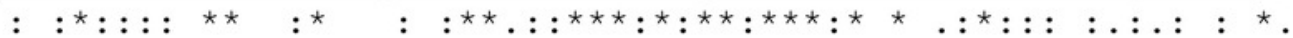

Sso_ArnR VQTVVLTSEGRKIAYKVPSLIKIRNNLFLRLLLKITFS ISYESALMKLMVFFALSSPIII Saci_ArnR IYKCVLMNEGKRLLFRLPEFTKMKNNLPLKLLLRLTNSYTLEMANVKVMGF I L I SLPLLM Saci_ArnR1 KKIYVLTDESRKLVSRLPELTRLKRNLPLKILLKLTGSYRYEIAITKVMLFNVISI PVLM

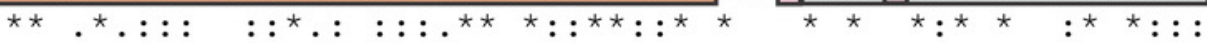

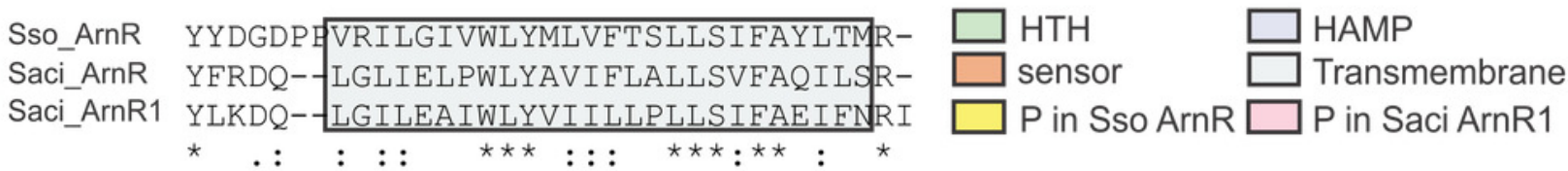

B

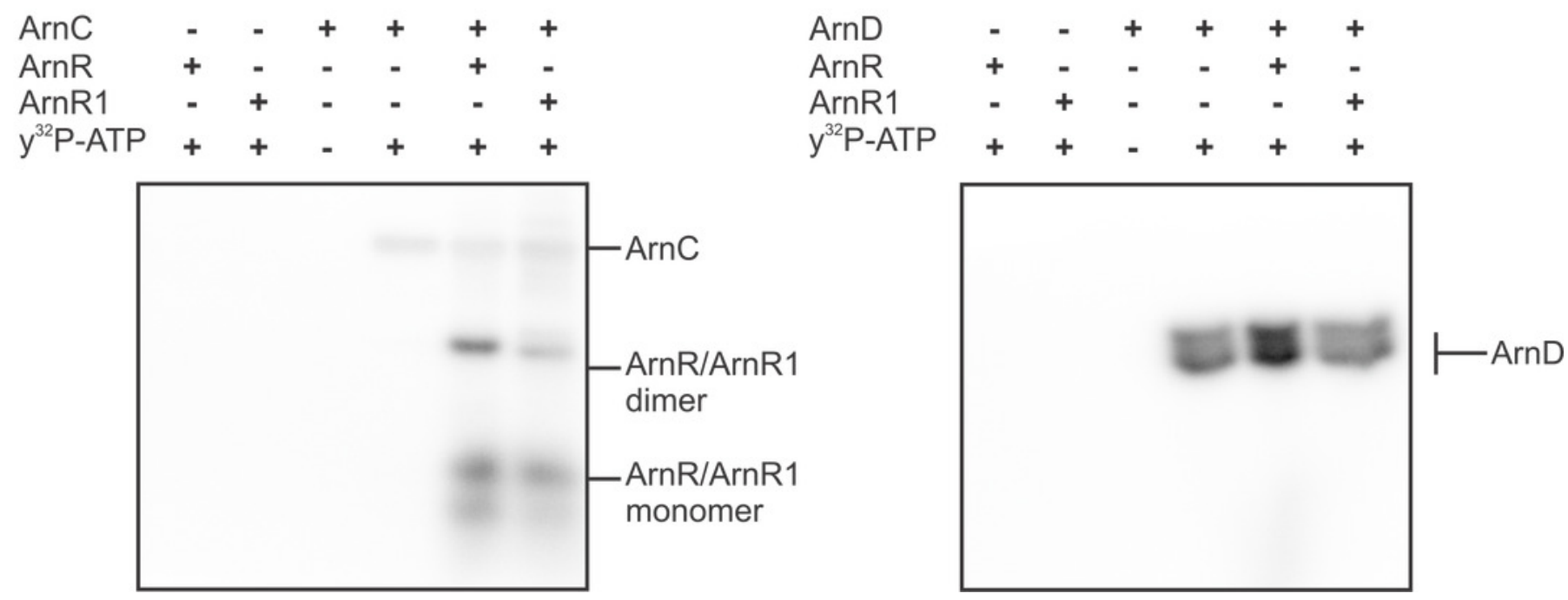




\section{Figure 4}

Both ArnR boxes are required to facilitate ArnR and ArnR1 binding to pflaB.

A. flaB (upper) promoter sequence. Numbers correspond to the distance respective to the transcription start site (TSS). The position of core promoter elements and cis-regulatory sequences is depicted in boxes (Lassak et al., 2013) BRE: factor B recognition element, TATA: TATA-box. pflaB ${ }^{41}$ (black box) comprises the region of $-43--84$ and includes both ArnR boxes. The $15 \mathrm{bp}$ regulatory elements ArnR box-1 and box-2 are highlighted in green and fragments used in this assay covering the sequence of either box are circled by dashed lines. B. Net fluorescence obtained in microscale thermophoresis (MST) assays with increasing amounts of ArnR (left graph) and ArnR1 (right graph). 0.156 - $18 \mu \mathrm{M}$ ArnR or ArnR1 were titrated in 2.5 nM Alexa Fluor 647 labeled DNA and subjected to thermophoresis. Curves were obtained from two independent experiments performed in duplicate. Fluorescence was normalized $(\Delta \mathrm{F})$ by subtracting the lowest measured fluorescence value determined within each experiment from all measured fluorescence values. Obtained curves were fitted using nonlinear regression, with one site specific binding according to $\left(y=F_{\max } * X /\left(K_{D}+X\right)\right.$. 
A

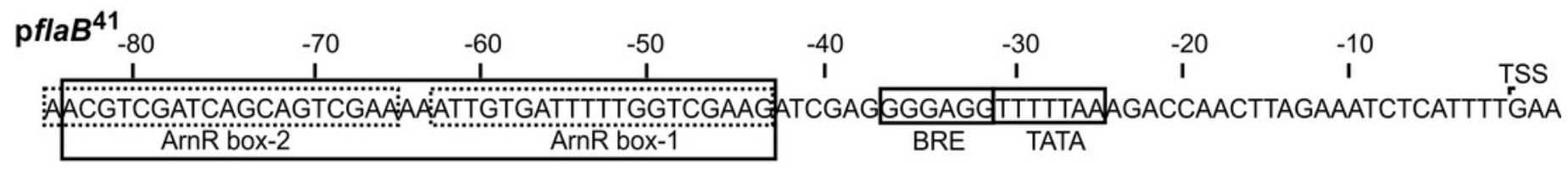

B
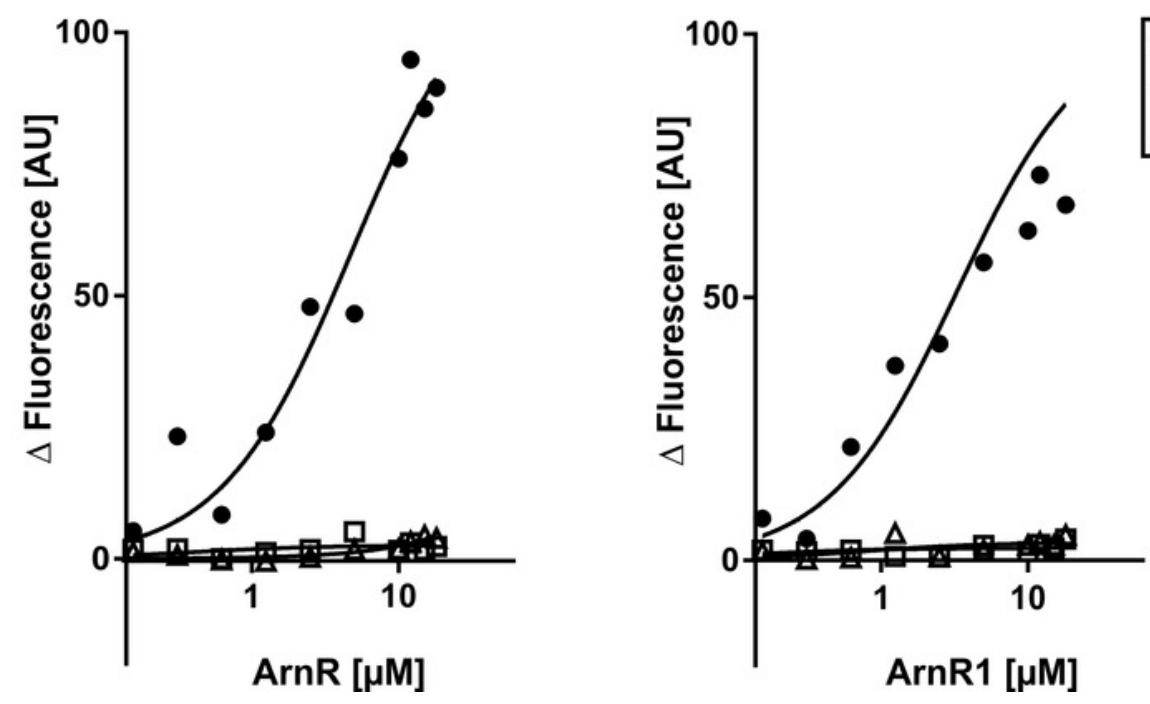

\begin{tabular}{l}
- pfla $B^{41}$ \\
\# box-1 \\
\# box-2 \\
\hline
\end{tabular} 


\section{Figure 5}

ArnR binds to promoter sequences of other T4P structures.

A. upsX, aapF and pSaci_2122 (- control) promoter sequences. Numbers correspond to the distance respective to the transcription start site (TSS). The positions of core promoter elements are depicted in boxes. BRE= factor $B$ recognition element, TATA=TATA-box. The pups $X$ fragment comprises the region of -38 - 79 (black box). The paapF fragment harbors the region of -41- -82. B. Net fluorescence obtained in microscale thermophoresis (MST) assays with increasing amounts of ArnR (left) and ArnR1 (right). $0.156-18 \mu \mathrm{M}$ of protein was titrated in 2.5nM Alexa Fluor 647 labelled DNA and subjected to thermophoresis. Curves were obtained from two independent experiments performed in duplicate. Fluorescence was normalized by subtracting the lowest measured fluorescence value determined within each experiment from all measured fluorescence values $(\Delta \mathrm{F})$. Obtained curves were fitted using non-linear regression, with one site specific binding according to $\left(y=F_{\max } * X /\left(K_{D}+X\right)\right.$. 
A

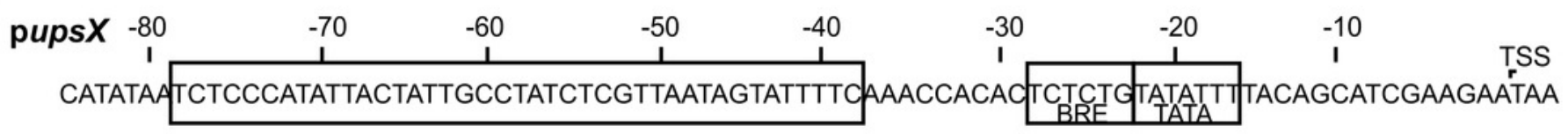

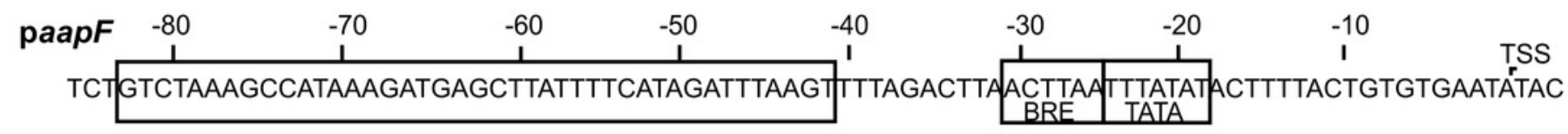

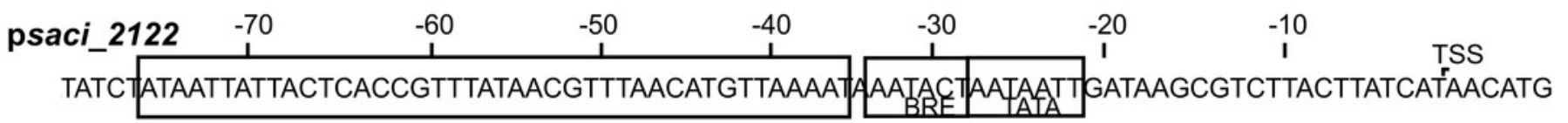

B
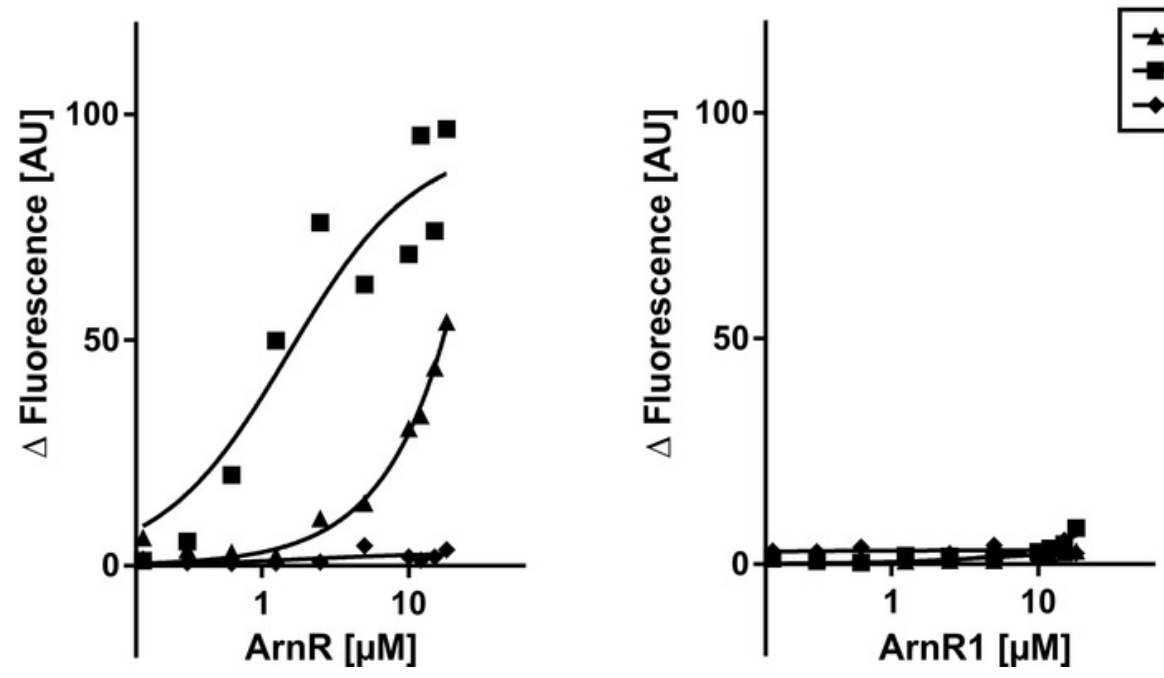


\section{Figure 6}

Transcript levels of aapF (black) and upsX (grey) in S.acidocaldarius MW001(wild-type) and $a r n R$ and $a r n R 1$ deletion mutants.

Gene expression is depicted as log2-fold change after normalization to the housekeeping gene alcohol dehydrogenase (adh, Saci_1690). Data were obtained from biological triplicates analyzed in duplicate and are given as means +- SD. Values that are significantly different compared to the WT (Student'st-test, $p \leq 0.05$ ) are indicated by asterisks. p-Value aapF transcript levels in $\triangle a r n R: 0.0031$; p-Value aapF transcript levels in DarnR1: 0.00004.8, . pValue ups $X$ transcript levels in $\square$ arnR: 0.00013, p-Value ups $X$ transcript level in darnR1: 0.06

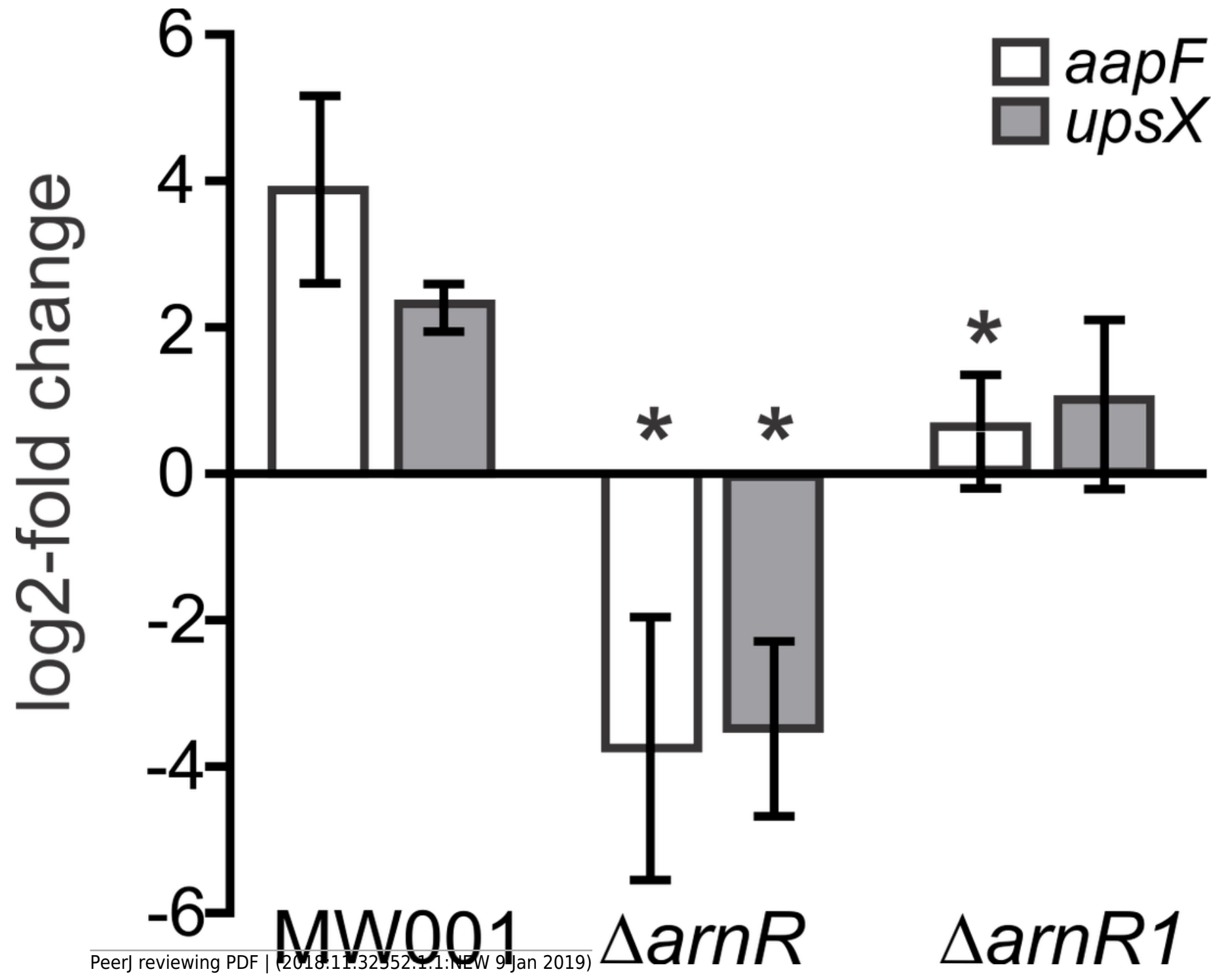




\section{Figure 7}

Cross-regulatory network of T4P-like surface structures of S. acidocaldarius.

Operon and structural organization of Aap-pilus (left), archaellum (middle) and Ups-Pilus (right) are shown. Known promoters of the operons are indicated by arrows. Orange arrows indicate pathways that are activated by nutrient limitation. Black arrows $=$ unknown physiological conditions. - = repression, $+=$ activation. $\mathrm{P}=$ phosphorylation. All by now identified key players of the archaellum regulatory network (Arn) and their regulatory activity on the Aap-, Ups-pili and archaellum is shown. ArnR is induced by nutrient limitation, and binds to flaB, aapF and ups $X$ promoters. ArnR 1 is induced by unknown physiological conditions and binds to $a a p F$ and flaB promoters. Both proteins are phosphorylated by ArnC. The membrane bound sensor kinase ArnS is induced by nutrient limitation, but targets of phosphorylation are so far unknown. AbfR1, a repressor of aapA and activator of flaB is also phosphorylated by ArnC (Orell et al2013; Li et al, 2018). ArnA and ArnB are archaellum repressors under nutrient rich conditions, and are phosphorylated by ArnC and ArnD (Reimann et al, 2012). The phosphatase PP2A is involved in regulating the phosphorylation status of ArnA and ArnB (Reimann et al., 2013). 


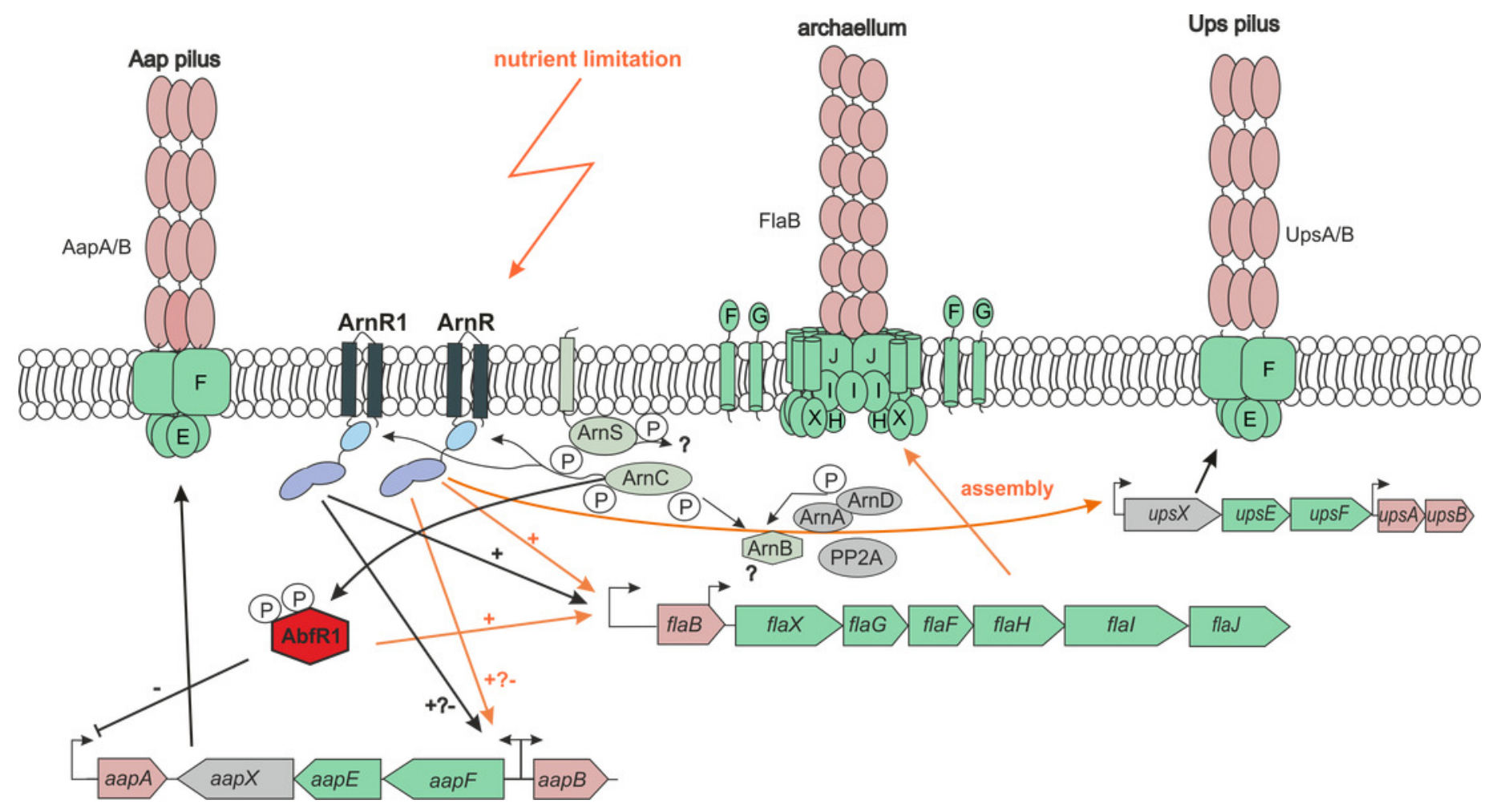

